\title{
HUMAN FACTORS AND VOICE INTERACTIVE SYSTEMS
}


THE KLUWER INTERNATIONAL SERIES IN ENGINEERING AND COMPUTER SCIENCE 


\section{HUMAN FACTORS AND VOICE INTERACTIVE SYSTEMS}

edited by

\section{Daryle Gardner-Bonneau}

Office of Research, Michigan State University

Kalamazoo Center for Medical Studies

Kalamazoo, Michigan

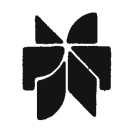

Springer Science+Business Media, LLC 
ISBN 978-1-4757-2982-5

ISBN 978-1-4757-2980-1 (eBook)

DOI 10.1007/978-1-4757-2980-1

\section{Library of Congress Cataloging-in-Publication Data}

A C.I.P. Catalogue record for this book is available from the Library of Congress.

Copyright (C) 1999 by Springer Science+Business Media New York Originally published by Kluwer Academic Publishers in 1999

Softcover reprint of the hardcover 1st edition 1999

Screen shots on Pages 212 and 213 reprinted by permission from Microsoft Corporation.

All rights reserved. No part of this publication may be reproduced, stored in a retrieval system or transmitted in any form or by any means, mechanical, photocopying, recording, or otherwise, without the prior written permission of the publisher, Springer Science+Business Media, LLC 
This book is dedicated to the memory of Dr. Gary K. Poock - pioneer, mentor, colleague, and friend 
Table of Contents

List of Contributors $\quad$ XV

$\begin{array}{ll}\text { Preface } & \text { xvii }\end{array}$

Acknowledgements $\quad$ xxiii

1 Speech User Interface Evolution

John Karat, Jennifer Lai, Catalina Danis and

Catherine Wolf

2

Spoken Natural Language Dialogue Systems:

User Interface Issues for the Future

Susan J. Boyce

Evaluating the Quality of Synthetic Speech

Alexander L. Francis and Howard C. Nusbaum

Phonological Rules for Speech Synthesis

Michel Divay

Synthesized Speech for Evaluation of Children's Hearing and Acoustic-Phonetic Perception Mária Gósy

Universal Access and Assistive Technology John C. Thomas, Sara Basson, and Daryle Gardner-Bonneau

Guidelines for Speech-Enabled IVR Application

Design

Daryle Gardner-Bonneau

$8 \quad$ Limiting Factors of Automated Telephone Dialogues

David G. Novick, Brian Hansen, Stephen Sutton, Catherine R. Marshall

Why Do People Dial Wrong Numbers?

Arnold M. Lund 
viii

11 IVR for Banking and Residential Telephone Subscribers Using Stored Messages Combined with a New Number-to-Speech Synthesis Method Gábor Olaszy and Géza Németh

Voice Messaging User Interface

Harry E. Blanchard and Steven H. Lewis

A New Design Framework for Computer-Telephony Integration (CTI)

Martha J. Lindeman

14 The Future of Voice Interactive Applications

Daryle Gardner-Bonneau

Index 


\section{List of Figures}

2

Figure 1. Ratings of the most preferred method of confirming digit strings.

Figure 2. Percentage of Callers Who Judged the Delay Acceptable.

4

Figure 1. General synopsis of a rule-based expert system.

Figure 2. Input and output buffers.

Figure 3. Left context for rule 1.

Figure 4. Left and right contexts for rule 2.

Figure 5. Left context in the output buffer.

Figure 6. Morph decomposition for classified.

Figure 7. Liaison for French.

Figure 8. Elision for French.

5

\section{Synthesized Speech for Evaluation of Children's} Hearing and Acoustic-Phonetic Perception

Figure 1. Demonstration of the basic principle of the $\mathrm{GOH}$ method.

Figure 2. Interrelationship of incorrect responses to the synthesized words (\%) and the pure tone audiometry values.

Figure 3. Interrelationship of correct responses for the synthesized words (\%) and the compliance (c) values.

Figure 4. Interrelationship of incorrect responses for synthesized words $(\%)$ and the values of pressure $(p)$.

Figure 1. Human-computer interaction process.

Figure 2. Relationship between effectiveness and naturalness.

Figure 3. McGrath task circumplex.

Figure 1. A typical $3 \times 4$ key layout. 
Figure 2. Number entry accuracy as a function of digit string length.

Figure 3. Number entry speed as a function of digit string length. 190

Figure 4. Number entry accuracy as a function of digit string length. 194

Figure 5. Number entry speed as a function of digit string length. 195

Figure 6. Inter-digit entry time as a function of digit string length. 196

Figure 7. Errors as a function of position in 4-digit strings. 198

Figure 8. Errors as a function of position in 10-digit strings. 198

10 Re-Engineering The Speech Menu 205

Figure 1. The Original Menu. 210

Figure 2. Text-Based Menu. 211

Figure 3. Contemporary Pull-Down Menu. 212

Figure 4. Graphical Toolbar. 213

$\begin{array}{lll}\text { Figure 5. User-First Strategy. } & 217\end{array}$

Figure 6. Main Selection Node. 220

Figure 7. Common Sense logic. 222

Figure 8. Interactive List Device. 228

Figure 9. Query and Selection Logic. 229

11 IVR for Banking and Residential Telephone Subscribers Using Stored Messages Combined with a New Number-to-Speech Synthesis method

Figure 1. Comparison of the old and the new methods of concatenation.

Figure 2. The pronunciation form of the sample numbers during recording.

Figure 3. Block diagram of NTS algorithm implementation. 252

12 Voice Messaging User Interface

Figure 1. A typical flow of events in a caller interface.

Figure 2. A typical menu hierarchy for a voice mail subscriber user interface. 


\section{List of Tables}

1

Table 1. General characteristics of speech recognition systems considered here.

Table 2. MedSpeak design solutions.

Table 3. Error causes and recovery methods.

2

Spoken Natural Language Dialogue Systems: User Interface Issues for the Future

Table 1. An example dialogue (request for an area code) for each of the prompt styles tested.

Table 2. Ratings of overall satisfaction with each version of the system.

Table 3. Ratings of satisfaction with the speed of the systems with actual transaction times in parentheses.

Table 4. Ratings of satisfaction with system performance.

Table 5. Prompts tested in the Initial Greeting Experiment.

Table 6. Average number of words callers used to state their request as a function of the initial greeting.

Table 7. Callers responses to Explicit and Implicit Confirmations.

Table 8. Responses to incorrect confirmations classified into categories based upon semantic content of response.

Table 9. Responses to correct confirmations classified into categories based upon the semantic content of the response.

Table 10. Percentage of responses to reprompts by category. 56

Table 11. Percentage of Responses in the Productive Strategies.

5

\section{Synthesized Speech for Evaluation of Children's} Hearing and Acoustic-Phonetic Perception

Table 1. Acoustic elements of some synthesized speech sounds.

Table 2. Percentage correct recognition of filtered natural and synthesized words.

Table 3. A six-year-old boy's responses to synthesized words.

Table 4. $\quad \mathrm{GOH}$ answer sheet for hearing screening. 
Table 5. Hearing screening results in kindergartens.

Table 1. Information flow of various tasks.

Table 2. System features.

Table 3. User features.

Table $4 . \quad$ Modality features.

Table 5. Task features.

Table $6 . \quad$ System $\mathrm{x}$ user features.

Table $7 . \quad$ System $x$ modality features.

Table 8. System $x$ task features.

Table 9 . Modality $x$ user features.

Table 10. Modality $x$ task features.

Table 11. User $x$ task features.

Table 12. User $x$ system $x$ task features.

9

Table 1. Examples of digit strings.

10

Table 1. Features and Benefits of Mechanistic Devices. 208

Table 2. DTMF Menu. 214

Table 3. Verbatim Prompting. 215

Table 4. Initial Prompt. 218

Table 5. List Introduction Announcements. 225

Table 6. Prompting by Example. 227

Table 7. Goal-Oriented Queries. 227

Table 8. Point and Speak. 230

11 IVR for Banking and Residential Telephone Subscribers Using Stored Messages Combined with a New Number-to-Speech Synthesis method

Table 1. The basic number elements in four languages for the traditional concatenation sythesis of any cardinal number up to 999 billion. 
Table 2. The most important regressive co-articulation rules for the last and first sounds of the number elements.

Table 3. The most important progressive co-articulation rules for the last and first sounds of the number elements.

Table 4. Examples for the algorithm for the concatenation rules for Hungarian.

Table 5. Example of determining the list of number elements and the source from which they will be cut (for English).

Table 6. Responses for question (1).

Table $7 . \quad$ Judgments of speech quality.

Table 8. Speech quality for complex messages.

12

Voice Messaging User Interface

Table 1. ISO/IEC 13714 standardized features. Integration (CTI)

Table 1. A matrix framework for discovering potential problems in the design of a computer-telephony integration (CTI) system.

Table 2. Cell names and examples for an "Outbound" row added to Table 1. 


\section{LIST OF CONTRIBUTORS}

Bruce Balentine

Same Page Design Group

\section{Sara Basson}

IBM T.J. Watson Research Center

Harry E. Blanchard

AT\&T Labs

Susan J. Boyce

AT\&T

Catalina Danis

IBM T. J. Watson Research Center

Michel Divay

Université de Rennes

Institut Universitaire de Technologie

France

Alexander L. Francis

Department of Psychology

The University of Chicago

Daryle Gardner-Bonneau

Michigan State University

Kalamazoo Center for Medical Studies

Mária Gósy

Phonetics Laboratory,

Research Institute for Linguistics,

Hungarian Academy of Sciences

Brian Hansen

Oregon Heath Sciences University

John Karat

IBM T. J. Watson Research Center

Jennifer Lai

IBM T. J. Watson Research Center
Steven H. Lewis

AT\&T Labs

Martha J. Lindeman

Users First, Inc.

Arnold M. Lund

U S WEST Advanced Technologies

Catherine R. Marshall

CollabTech, Inc.

Géza Németh

Dept. of Telecommunications and

Telematics

Technical University of Budapest

Hungary

David G. Novick

EURISCO, and

Oregon Graduate Institute

Howard C. Nusbaum

Department of Psychology

The University of Chicago

Gábor Olaszy

Phonetics Laboratory,

Research Institute for Linguistics,

Hungarian Academy of Sciences

Stephen Sutton

Fluent Speech Technologies, Inc.

John C. Thomas

IBM T.J. Watson Research Center

Catherine Wolf

IBM T. J. Watson Research Center 


\section{PREFACE}

A number of books have been written about speech technologies. Most of them are devoted, specifically, to the technologies under development, rather than the application of these technologies in the real world. It has been only recently that people have started writing books about the technology in use (e.g., Baber and Noyes, 1993; Markowitz, 1996; Raman, 1997; Schmandt, 1994; Syrdal, Bennett. and Greenspan (1995). All of them consider human factors engineering to a greater or lesser degree but, curiously, some (e.g., Schmandt, 1994; Raman, 1997) never emphasize the vital role that human factors has played, and will continue to play, in the design of successful applications employing these technologies.

Human factors engineering has a long history dating back, at least, to the industrial efficiency studies of the early part of this century (see Sanders and McCormick (1993) for a discussion of the profession's history). It is the discipline that strives to ensure that technologies are used in a way that enhances human productivity and task performance, minimizes errors, and ensures safety. As a discipline, it has had an impact in virtually every area of human endeavor. From the design of aircraft cockpits and nuclear power plant control rooms, to the design of easy-grip gardening tools and the toothbrush in your bathroom, the application of human factors engineering has helped to ensure that products and systems are easy to use, effective, and safe. It does this through methods, tools, and techniques that focus on the user, or the potential user, from the very beginning of the design process through to the finished product. Its principal tenet is that, to be successful, applications of technologies must be designed with due consideration of the user; applications that neglect the user interface are destined to fail.

One of the interesting, and frustrating, things about this field is that people acknowledge its contribution, primarily, when a product, piece of equipment, or system under discussion is lacking good human factors engineering. They lament that it is unusable, difficult to learn, prone to errors, and unable to meet their expectations and fulfill their goals. Alternatively, when products are successful, good human factors engineering is rarely credited with the success. This is one of the reasons I wanted to write this book - to showcase what it is that human factors professionals do, behind the scenes, that contributes to successful products.

Another characteristic of the human factors field is the fact that its literature is scattered everywhere. Because human factors engineering applies to the design of nearly everything, papers get presented and published in many different forums. 
Papers about telecommunications get published in telecommunications journals, papers about medical systems in medical journals, and papers about speech technologies get presented and published through the various forums devoted to these technologies. Human factors engineering does have its own national organization in the United States (The Human Factors and Ergonomics Society), which publishes papers on human factors engineering in all areas to which it is applied and sponsors an annual conference that addresses human factors across all domains of application. However, many technology developers in individual application domains may never encounter these journal and conference papers or this organization. To complicate matters further, for every human factors professional whose primary professional affiliation is The Human Factors and Ergonomics Society, there is another who is more involved with the Association for Computing Machinery (ACM) and, specifically, its Special Interest Group on Computer-Human Interaction (SIG CHI). Therefore, many professionals in the human factors field may not encounter each other on a regular basis, because they attend different professional meetings. Thus, another reason I wanted to write this book was to bring much of the human factors literature related to speech technology together in one place.

Finally, many of the books written on speech technology applications emphasize the desktop environment. I am not aware of any that focus on over-the-telephone use of speech technologies, even though such applications are among the most ubiquitous, at least in the United States. There is an especially rich history of human factors work in telephony, dating back to Bell Laboratories at the turn of the century, and much of the human factors contribution to speech technology applications has been in the area of interactive voice response (IVR) systems. Nearly half of this book is devoted to human factors work on speech-enabled telephony applications, both those with touch-tone interfaces and those under development more recently that employ speech recognition front-ends.

I had hoped to write my own book about human factors and speech technologies. However, things being what they are in the life of a working mother these days, it just wasn't in the cards. But rather than abandon my goals, I decided to pursue them with the assistance of some of my distinguished colleagues.

The resulting book is divided, roughly, into three sections devoted to 1) automatic speech recognition; 2) synthetic speech; and 3) interactive voice response. Some of the chapters are devoted to specific applications of the speech technology, while others are issue-oriented or provide a comprehensive view of the work in a specific applications area. Together, they give a fairly comprehensive picture of the kinds of work human factors professionals do, and the ways in which they accomplish it.

The first two chapters are devoted to applications of automatic speech recognition (ASR) and a discussion of work ongoing in the area of natural language processing. In the first chapter, John Karat and his colleagues at IBM discuss, in detail, the design work they have done on the user interfaces of several products. One of these products in particular - MedSpeak - is enjoying wide acceptance in the medical transcription marketplace. IBM's attention to the needs of users, described in detail for all of the applications discussed, serves to highlight the 
importance of the up-front work on needs assessment that can be a major determinant of an application's success.

Natural language processing is the logical next step for speech technology, but its application lies somewhere in the future. In Chapter Two, Susan Boyce, of AT\&T, demonstrates with copious examples just why this is the case. At the same time, she highlights the progress that has been made in the last several years. Understanding communication at the level of conversations is required for natural language processing, and it is a very difficult task, indeed.

The next three chapters, all very different, are devoted to synthetic speech. The first, by Alexander Francis and Howard Nusbaum, provides a comprehensive view of the factors that determine the quality of synthetic speech - namely, intelligibility and naturalness - and the tools and techniques used in its evaluation. The following two chapters give the reader a glimpse at some of the very difficult work that makes synthetic speech applications possible. In Chapter 4, Michel Divay describes the challenging and tedious effort involved in doing grapheme-to-phoneme transcription, both for English and for French. The fact that such transcription is language-dependent serves to illustrate just how much work is involved to convert text to speech in any language, and how daunting the task may be to achieve this result for the many languages of the world that have not been synthesized to date.

It has long been my belief that one of the areas in which speech technologies could best serve humanity is in the service of people with disabilities. Although some well known applications exist, and an innovative paper or two appears occasionally, we have only scratched the surface of what is possible with respect to assistance for people with visual, speech, hearing, language, and mobility impairments. One of the areas in which speech technologies have had little application, but where much is possible, is in the assessment of speech, language, and hearing disorders and therapies for these disorders. Thus, it is a special pleasure to include Maria Gósy's contribution (Chapter 5) on the use of synthesized speech for evaluating children's hearing and acoustic-phonetic perception. Chapter 6 continues with this theme, and presents material on the uses of both synthetic speech and speech recognition in assistive technology, and to achieve the goal of universal access - the design of systems to be usable by everyone, regardless of his or her level of disability.

Seven of the remaining eight chapters are devoted to telephony-based applications of speech technology. In the first of these (Chapter 7), I describe efforts to develop user interface guidelines for interactive voice response (IVR) applications, and how U.S. approaches to IVR design, predicated on the availability of touch-tone technology, need to change now that speech recognition has "come of age." In the creative chapter that follows, David Novick and his colleagues discuss a task-based approach for determining whether development of an IVR application is appropriate, given the particular features of the task situation involved.

When the prospectus for this book was evaluated, several reviewers questioned the inclusion of Arnold Lund's contribution (Chapter 9), because it does not address the use of speech technology, specifically. It has remained, however, for two reasons. First, because touch-tone-based applications for IVR systems are predominant in the United States, and will be for some time to come, Lund's analysis of touch-tone dialing errors will continue to be relevant to the design of 
these applications. Second, this chapter exemplifies the quantitative, empirical nature of much of the work human factors specialists do. For the many speech scientists and electrical engineers out there who tend to consider human factors work as "soft and squishy" and unquantifiable, this contribution, which is typical of those found in human factors journals, demonstrates that there is as much science as art in this field.

Chapter 10, by Bruce Balentine, offers a view that appears contradictory to the one I present in the first IVR chapter, at least at first glance. However, this is not the case, really. While I discuss how IVR applications can and should change as a result of the introduction of automatic speech recognition, Bruce shows us how we can live within the framework of the menu-driven design approach we've created in the U.S., whether an application is speech-enabled or not. Endlessly creative, Bruce shows us how to make menu-based designs work, by careful attention to the construction of the IVR dialogue.

The second of two chapters from the Research Institute for Linguistics in Budapest, Hungary (the first was Gósy's chapter), Chapter 11 describes the process used to develop high quality concatenated speech for a banking-related IVR application. The authors, Gábor Olaszy and Géza Németh, also describe their evaluation study of a resulting application, and discuss both the perception and the acceptability of the synthesized speech.

Chapter 12, by Harry Blanchard and Steven Lewis, provides a comprehensive treatment of voice mail applications. Detailed design guidelines are presented, and the authors discuss the ways in which voice mail is now being integrated with email and FAX services to achieve unified messaging. Finally, Martha Lindeman describes in Chapter 13 an approach to computer-telephony integration (CTI) problems through a design framework that considers the dimensions of time and complexity in a call's life cycle.

In the concluding chapter, I provide some final thoughts about applications that received limited attention in the book and offer some musings about the future of this technology and the continuing role of human factors in speech-enabled application design. It is my hope that speech application developers will derive benefit from the many "lessons learned" presented in this book, and will make use of both human factors expertise and the techniques and tools of this field as they design tomorrow's applications.

\section{Daryle Gardner-Bonneau}

\section{REFERENCES}

Baber, C., and Noyes, J. M., Eds. (1993). Interactive speech technology: Human factors issues in the application of speech input/output to computers. London: Taylor \& Francis.

Markowitz, J. A. (1996). Using speech recognition. Upper Saddle River, NJ: Prentice-Hall. 
Raman, T. V. (1997). Auditory user interfaces: Toward the speaking computer. Boston: Kluwer Academic Publishers.

Sanders, M., and McCormick, E. J. (1993). Human factors in engineering and design ( $7^{\text {th }}$ ed.). New York: McGraw-Hill.

Schmandt, C. (1994). Voice communication with computers: Conversational systems. New York: Van Nostrand Reinhold.

Syrdal, A., Bennett, R., and Greenspan, S., Eds. (1995). Applied speech technology. Boca Raton: CRC Press. 


\section{ACKNOWLEDGEMENTS}

In my professional career, I've edited individual articles, special issues of journals, and even a magazine, but never a book. Thus, I must thank, first, the contributors, who trusted me with their manucripts and cooperated marvelously during the editing process, maintaining their support, good humor, and high spirits throughout. Some are friends; others I'd never met and know only by reputation. But I'm proud to call all of them my colleagues. I also thank Alex Greene at Kluwer, who backed this project and provided gentle nudges, as needed. It would have been impossible to complete this project, however, without the love and support of those dearest to me. In this regard, I thank my son, Nicholas, for enduring so many evenings of fast food, and for tolerance, well beyond his years, during those days when I had so little quality time to spend with him. Last, but only on this page, I thank John Bonneau husband extraordinaire - for all the time and effort he expended to produce the camera-ready version of the book. More importantly, I thank him for giving me, through his endless love and support, the courage to pursue all my dreams and the confidence to capture so many of them. 